\title{
CD26 Expression in Mature B-cell Neoplasms and its Prognostic Impact on B-Cell Chronic Lymphocytic Leukemia
}

Doaa M. El Ghannam ${ }^{1 *}$, Mona M. Taalab², Hayam F. Ghazy ${ }^{3}$, Eman M. Abdul Salam ${ }^{4}$ and Iman M. Fawzy

${ }^{1}$ Department of Clinical Pathology, Faculty of Medicine, Mansoura University, Egypt

${ }^{2}$ Clinical Hematology unit, Internal Medicine Department, Faculty of Medicine, Mansoura University, Mansoura, Egypt

${ }^{3}$ Medical Oncology unit, Internal Medicine Department, Faculty of Medicine, Mansoura University, Mansoura, Egypt

${ }^{4}$ General Medicine Department, Faculty of Medicine, Azhar University, Cairo, Egypt

${ }^{5}$ Departments of Laboratory Medicine, Mansoura Fever Hospital, Ministry of Health, Mansoura, Egypt

\begin{abstract}
CD26/dipeptidyl peptidase IV (DPPIV) is a multifunctional membrane protein and it is strongly upregulated in activated B-cells. We aimed to evaluate CD26 expression in mature B cell neoplasms, and its prognostic role in B cell chronic lymphocytic leukaemias (B-CLL). CD26 expression was evaluated by flow cytometry in various B cell neoplasms. CD26 expression was high in MMs and HCLs, variable in B-CLLs and in CD5neg B-CLPDs. Kaplan-Meier curves revealed a significantly shorter progression free survival (PFS), and lymphocytic doubling time (LDT) in the CD26 high expression group ( $p=0.014,0.024$ respectively). High CD26, CD38 and/or ZAP70 showed significantly shorter PFS, ( $p=0.020,0.022$ respectively) and LDT ( $p=0.024,0.024$ respectively) when compared to both low expression CD26, CD38 and/or ZAP70. CD26 expression may identify subsets of B-CLL patients with an unfavorable clinical outcome, thus suggesting its potential role as a marker in a future routine cytofluorimetric panel for B-CLLs.
\end{abstract}

Keywords: B-cell mature lymphoid tumours; B-cell chronic lymphocytic leukaemia; CD26; CD38; ZAP-70; Expression; Progression free survival, Lymphocytic doubling time, Prognosis

\section{Abbreviations}

B-CLL: B Cell Chronic Lymphocytic Leukaemias; B-CLPD: B Cell Chronic Lymphoproliferative Disorders; DPPIV: Dipeptidyl Peptidase IV; FITC: Fluorescein Isothiocyanate; HCL: Hairy Cell Leukaemias; LDT: Lymphocytic Doubling Time; mAbs: Monoclonal Antibodies; MM: Multiple Myeloma; OS: Overall Survival; PBS: Phosphate Buffered Saline; PE: Phycoerythrin; PerCp: Peridinin-Chlorophyll Proteins; PFS: Progression Free Survival; RT: Room Temperature; Sig: Surface Immunoglobulin; ZAP-70: Zeta-Chain-Associated Protein Kinase.

\section{Introduction}

CD26 or Dipeptidyl peptidase IV (CD26/DPPIV) is a unique multifunctional $110 \mathrm{kDa}$ membrane-bound glycoprotein, belongs to the serine protease family, acts as receptor, binding and proteolytic molecule. The crystal structure indicates that tetramerization of DP IV is a key mechanism to regulate its interaction with other components. A dipeptide mimicking inhibitor complexed to the active site discloses key determinants for substrate recognition. It is expressed on a variety of tissues including $\mathrm{T}$ lymphocytes, endothelial and epithelial cells. CD26 plays an important role in immune regulation, signal transduction, and apoptosis [1]. Studies have suggested that CD26 plays a regulatory role in the neoplastic transformation and progression of various types of tumours, and it may also play a role in tumour migration and metastasis as a result of its ability to bind extracellular matrix proteins $[1,2]$. It is thought that CD26 plays an important role in hematological malignancies, mainly in aggressive subtypes of T-cell non-Hodgkin lymphoma in which it is highly expressed by neoplastic cells $[3,4]$. Although CD26 expression is very low in B-cells, it is greatly up regulated following activation [5].

The B-cell neoplasms are a biologically heterogenous group of malignant diseases characterized by accumulation of mature $\mathrm{B}$ lymphocytes in the bone marrow, peripheral blood and lymphoid tissue [6]. B cell chronic lymphocytic leukemia (B-CLL) is an accumulative disease of slowly proliferating lymphocytes that develops in the aging population. Whereas some patients with B-CLL have an indolent course and die after many years from unrelated causes, others progress very rapidly within a few years from this currently incurable leukemia [7]. Thus, it is more important than ever to develop sensitive stratification parameters to identify patients with poor prognosis.

\section{Subjects and Methods}

\section{Subjects}

The present study involved 100 newly diagnosed patients with mature B-CLPD who were evaluated at the time of diagnosis. On the basis of the WHO classification of neoplastic diseases of hematopoietic and lymphoid tissues [8], there were 58 cases of B-CLL, 7 cases of hairy cell leukaemia (HCL), 23 cases of CD5neg B-CLPD and 12 cases of multiple myeloma (MM). All patients were diagnosed and followed up between 2009 and 2013 in Masnoura Oncology Center, Mansoura, Egypt. In addition to 10 control subjects of matched age and sex were enrolled in the study. Informed consent was provided by all subjects.

The study was based on 58 (40 males, 18 females) consecutive, previously untreated CLL, 7 HCL (5 males, 2 females), 23 CD5 negative LPD ( 15 males, 8 females) and 12 multiple myeloma ( 8 males, 4 females). Mean age of CLL, HCL, CD5 negative LPD and multiple

*Corresponding author: Doaa M. El Ghannam, Department of Clinical Pathology, Faculty of Medicine, Mansoura University, Egypt, Tel: +1062376246; Fax: 951032051; E-mail: doaamahmoud1970@yahoo.com

Received April 23, 2014; Accepted June 06, 2014; Published June 15, 2014

Citation: Ghannam DME, Taalab MM, Ghazy HF, Salam EMA, Fawzy IM (2014) CD26 Expression in Mature B-cell Neoplasms and its Prognostic Impact on B-Cell Chronic Lymphocytic Leukemia. J Blood Disorders Transf 5: 222. doi: 10.4172/2155-9864.1000222

Copyright: (c) 2014 Ghannam DME, et al. This is an open-access article distributed under the terms of the Creative Commons Attribution License, which permits unrestricted use, distribution, and reproduction in any medium, provided the original author and source are credited. 
Citation: Ghannam DME, Taalab MM, Ghazy HF, Salam EMA, Fawzy IM (2014) CD26 Expression in Mature B-cell Neoplasms and its Prognostic Impact on B-Cell Chronic Lymphocytic Leukemia. J Blood Disorders Transf 5: 222. doi: 10.4172/2155-9864.1000222

Page 2 of 7

myeloma groups was $60.47,68.14,59.04,60.92$ years respectively. B-CLL cases were classified at diagnosis according to Binet and Rai classifications. Patients required treatment, received chemotherapy following the Working Group for CLL criteria [9].

\section{Immunophenotype analysis}

Bone marrow aspirates or peripheral blood samples were collected on EDTA tubes and immediately transported to the flowcytometry laboratory. For surface antigen staining, the received samples were lysed using homemade lysing solution $(8 \mathrm{~g}$ Ammonium chloride, $1 \mathrm{~g}$ EDTA, and $0.1 \mathrm{~g}$ dihydrogen potassium phosphate in $11-10 \mathrm{x}-$ ), washed with phosphate buffered saline (PBS) until complete RBCs lysis and resuspended in appropriate amount of PBS. The cells were stained with different fluorescently labeled monoclonal antibodies (mAbs) according to manufacturer recommendations (Dakocytomation, Denmark, and Beckman Coulter, France). One hundred microliters of cell suspension were mixed with $10 \mu \mathrm{l}$ of the fluorescently labeled $\mathrm{mAb}$ and incubated in the dark at room temperature (RT) for $30 \mathrm{~min}$. Washing with PBS containing $2 \%$ bovine serum albumin was done twice and the pellet was resuspended in PBS and analyzed immediately on flowcytometer. For detection of cytoplasmic and nuclear antigens, IntraPrep Permealization Kit was used (Beckman Coulter, France). Fifty microliters of EDTA PB/BMA sample were mixed with $100 \mu \mathrm{l}$ of IntraPrep reagent 1 (fixative), incubated for $15 \mathrm{~min}$ at $\mathrm{RT}$ protected from light, and washed with PBS. $100 \mu$ of IntraPrep reagent 2 (permealization) were mixed with the cells and incubated for $5 \mathrm{~min}$ at RT without vortexing or shaking. The tube was shook carefully and manually for 2-3 seconds and then 10-20 $\mu \mathrm{l}$ of the mAb were added, vortexed, and incubated for 20 minutes in case of cytoplasmic antigens and for $1 \mathrm{~h}$ in case of nuclear antigens at RT protected from light. Then, the mixture was washed and resuspended in PBS and analyzed on the flowcytometer immediately. The mAbs were used in different combinations of fluorochromes; namely fluorescein isothiocyanate (FITC), phycoerythrin (PE) and peridinin-chlorophyll proteins (PerCP). Different combination of $\mathrm{mAb}$ against the following antigens were used: CD45-PerCP, CD10-FITC, CD5-FITC, CD19PerCP, CD20-PE, CD23-FITC, CD38-PE, CD 26-PE and FMC7 FITC (Becton Dickinson, Mountain View, CA) CD103-FITC (Immuno Quality Products, Groningen, The Netherlands); and CD79b-FITC (DAKO, Glostrup, Denmark). FITC-conjugated F (ab0) 2 fragments of rabbit anti-human Ig (DAKO, Glostrup, Denmark) were used for the SIg analysis. For ZAP-70, peripheral blood mononuclear cells were stained with CD3-PerCP and CD19-PE for 15 minutes at $4^{\circ} \mathrm{C}$ (Becton Dickinson), and washed and fixed/permeabilized using a Fix \& Perm kit (Caltag Laboratories, Burlingame, CA) according to the manufacturer's instructions. They were then washed and stained with an Alexa-Fluor 488-conjugated monoclonal antibody against ZAP-70. The immunophenotyping was performed on EPICS-XL flowcytometer (Coulter, Miami, Fl). The cells were analyzed with the most appropriate blast gate using the combination of forward and side scatters. An antigen was considered positive when the expression is at least $20 \%$ of the gated cells in cases of CD45, CD10, CD5, CD19, CD20, CD23, FMC7, CD103, CD79b and SIg. The expression of each marker was calculated in terms of percentage reactivity in CD19 cells. As previously reported, in the B-CLL series, values of $>30 \%$ and $20 \%$ positivity for CD38and ZAP-70 were used when evaluating correlations with CD26 and the survival curves [10-12].

\section{Definition of end points}

Progression free survival (PFS) is defined as the time from study entry until objective disease progression, first line treatment according to NCI Working Group guidelines, death or last follow-up. Overall survival (OS) was measured from diagnosis to last follow-up or death. Lymphocyte doubling time was measured from diagnosis to time of lymphocyte doubling. Factors contributing to lymphocytosis or lymphadenopathy other than CLL (e.g. infection) were excluded. All patients underwent first treatment at the time of documentation of progressive and symptomatic disease according to National Cancer Institute-Working Group guidelines [13].

\section{Statistical methods}

All of the statistical calculations were made using excel program and SPSS (statistical package for social science) program (SPSS, Inc, Chicago, IL) version 16. Qualitative data were presented as frequency and percentage. Chi square test was used to compare groups. Quantitative data were presented as mean and standard deviation. For comparison between two groups; student t-test and Mann-whitney test (for nonparametric data) were used. The associations between variables were tested by Spearman's correlation test. The best cut-off point for CD26 expression was sought by constructing receiver operating characteristic (ROC) curves. Kaplan-Meier test was used for survival analysis and the statistical significance of differences among curves was determined by Log-Rank test. The Cox proportional hazards regression model was chosen to assess the independent effect of covariables on progression free survival. N.B: $p$ is significant if $\leq 0.05$ at confidence interval 95 .

\section{Results}

\section{CD26 expression}

CD26 was positive in $50,85.7,56.5$, and $75 \%$, in CLL, HCL, CD5 negative CLPD and MM respectively (Figure 1). The proportion of CD19-positive neoplastic B-CLL cells expressing CD26 ranged from 2 to $97 \%$, with a median value of $10 \%$; (Figure 2). Fluorescence intensity was dim in the B-CLL and CD5neg B-CLPD, and bright in the HCL and MM cases. Figure 3 shows example of $\mathrm{CD} 26$ positive expression in CD19 cells in representative cases of our series of B-cell tumors.

\section{CD26 Cut off}

The best cut-off point for CD26 expression discriminating the patients who were diagnosed as B-cell neoplasms from controls was

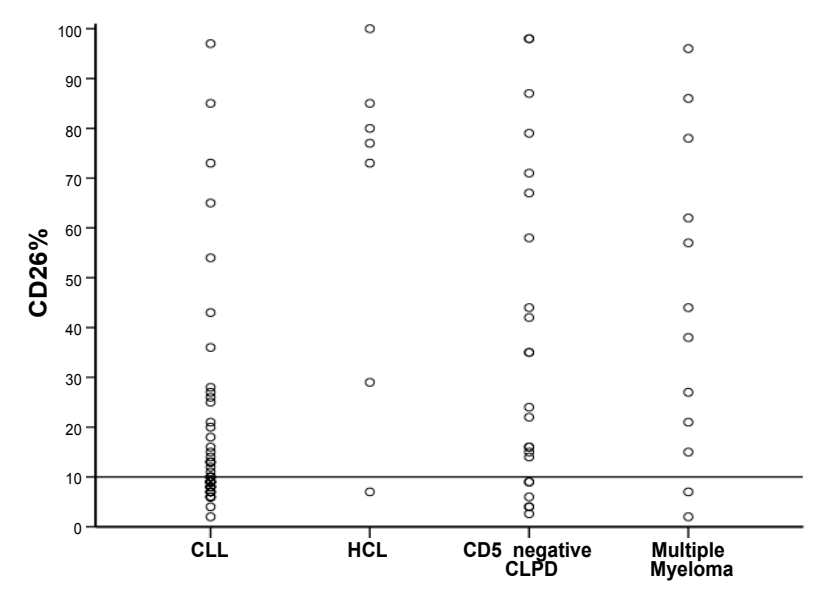

Figure 1: CD26 expression in the analyzed B-CLPD. Horizontal line demonstrate CD26 cutoff at $10 \%$ 


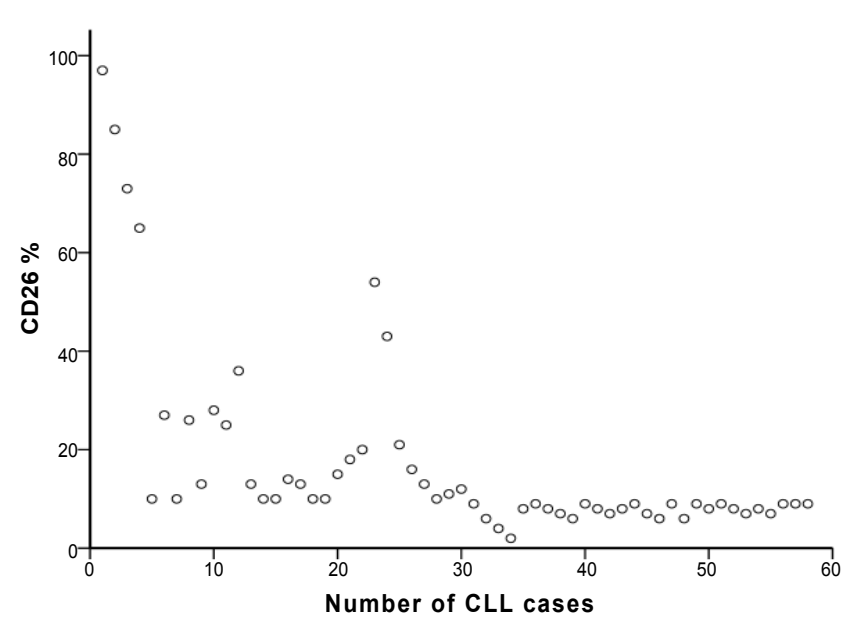

Figure 2: CD26 expression in the analyzed B-CLPD. Horizontal line demonstrate CD26 cutoff at $10 \%$.

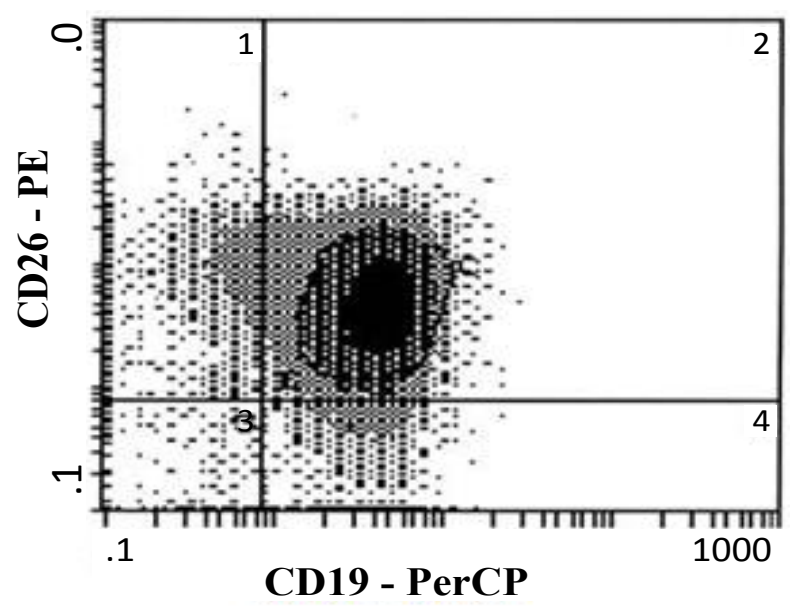

Figure 3: Example of CD26 positive expression on neoplastic CD19 positive cells in B-cell neoplasms. sought by constructing receiver operating characteristic (ROC) curves. The area under the ROC curve (AUC) $=0.842,95 \% \mathrm{CI}=0.770-0.913$, $\mathrm{p}<0.0001$, Cut off $=9.5$, sensitivity $85.6 \%$ and specificity $100.0 \%)$.

In the B-CLL cases, according to the obtained cut off value, 29 (50.0) cases had high CD26 expression (CD26 $6^{\text {high }}$ ), their values ranged from 10 to 97 with a mean 27.52; median 16.0 and 29 (50.0) cases had low $\mathrm{CD} 26$ expression $\left(\mathrm{CD} 26^{\text {low }}\right)$, their values ranged from 2 to 9 with a mean 7.62 and median 8.00 .

\section{Relationship of CD26 with markers of clinical characteristics}

No significant differences regarding age, sex, lymphadenopathy, hepatomegaly Binet, Rai staging, and hemoglobin in high versus low CD26 expression in CLL patients ( $p>0.05$ ). High CD26 expression showed significantly higher incidence of hepatomegaly, CD $38^{\text {high }}$ and ZAP70 ${ }^{\text {high }}(\mathrm{p}=0.027,<0.001,<0.001$ respectively), significantly higher total leucocytic count and LDH ( $\mathrm{p}=0.033,<0.001$ respectively), lower platelets count $(\mathrm{p}=0.040)$. Absolute lymphocytic count was higher in high CD26 expression group, although did not reach significant level $(\mathrm{p}=0.081)$ (Table 1).

\section{CD26, CD38 and ZAP70}

CD 38 was positive in $55.2 \%, 0 \%, 56.5 \%$, and $100 \%$ in CLL, HCL, CD5 negative LPD and MM respectively. Correlation analyses were made between $\mathrm{CD} 26$ reactivity and the expression of the other tested membrane antigens of relevance. High levels of CD38 ( $>30 \%$ CD19-positive cells) or ZAP-70 expression (>20\% CD19-positive cells) were found in respectively $32(55.2 \%)$ and $33(56.9 \%)$ of the 58 B-CLL patients. Spearman's test revealed a significant correlation between CD26 and CD38 reactivity's and between CD26 and ZAP70 expressions ( $\mathrm{rS}: 0.795, \mathrm{p}<0.001 ; \mathrm{rS}: 0.855 ; \mathrm{p}<0.001$ respectively). When applying Friedman correlation in B-CLL group; CD26, CD38 and ZAP70 values were highly correlated $\mathrm{p}<0.001$. CD26 and CD38 reactivities had different patterns in other B-cell neoplasms. There was a statistically significant Spearman's rank correlation coefficient in MM patients (rS: 0.671, $p=0.017$ ), but no significant correlations were found in the patients with CD5neg B-CLPD ( $r=-0.344, p=0.108)$ and HCL $(\mathrm{r}=0.679, p=0.094)$.
A)

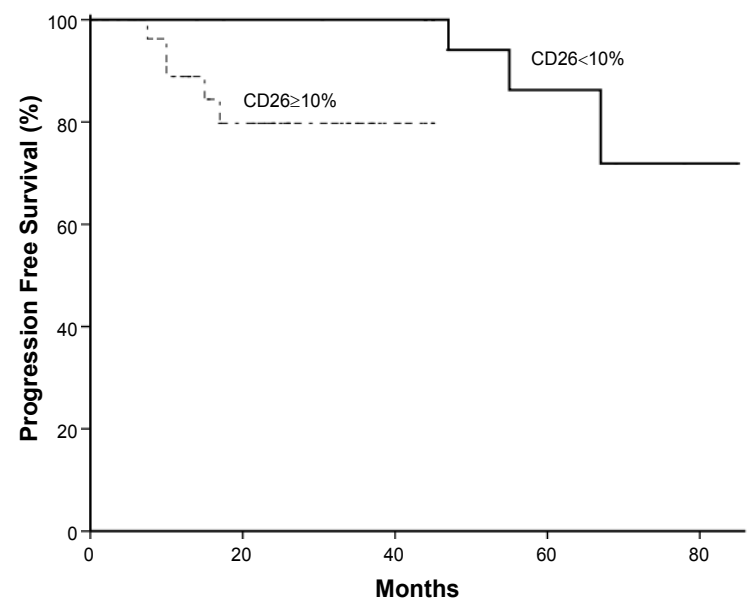

B)

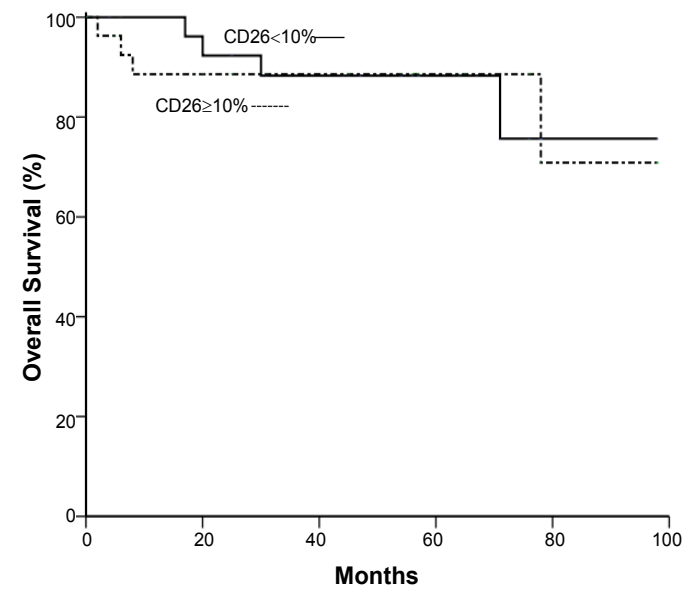

Figure 4: A )Progression free survival accrding to CD26 expression. B) Overall survival accrding to CD26 expression. 
Citation: Ghannam DME, Taalab MM, Ghazy HF, Salam EMA, Fawzy IM (2014) CD26 Expression in Mature B-cell Neoplasms and its Prognostic Impact on B-Cell Chronic Lymphocytic Leukemia. J Blood Disorders Transf 5: 222. doi: 10.4172/2155-9864.1000222

Page 4 of 7

\section{Relevance of CD26 expression as prognostic factor in B-CLL}

ROC analysis was used to explore the power of CD26 expression to distinguish patients who developed progressive disease from those with stable disease, and confirmed $10.5 \%$ as the best cut-off value (area under the curve $0.829, \mathrm{p}<0.0001$ ); all the subsequent data were therefore analyzed using a $10 \%$ threshold. When testing the prognostic relevance of CD26 expression in this study, B-CLL patients with high CD26 expression had significantly shorter progression free survival (PFS) (77.8 versus 38.4 months, $\mathrm{p}=0.014$ ). In addition, $79.8 \%$ of the CD26 $6^{\text {low }}$ and $94.1 \%$ of the CD26 $6^{\text {high }}$ patients had stable disease after 3years (Figure 4A). OS showed no significant differences between high and low CD26 groups ( $\mathrm{p}=0.955)$ (Figure $4 \mathrm{~B}$ ). Patients with high CD26 expression had significantly shorter time to develop lymphocytic doubling ( 11.5 versus 26.7 months, $\mathrm{p}=0.024$ ). In addition, $66.7 \%$ of the $\mathrm{CD} 26^{\text {low }}$ and $37.5 \%$ of the $\mathrm{CD} 26^{\text {high }}$ patients did not develop lymphocytic doubling after 12 months (Figure 5).

\section{Relevance of CD26-CD38, CD26-ZAP-70 expression as prognostic factors in $\mathrm{B}-\mathrm{CLL}$}

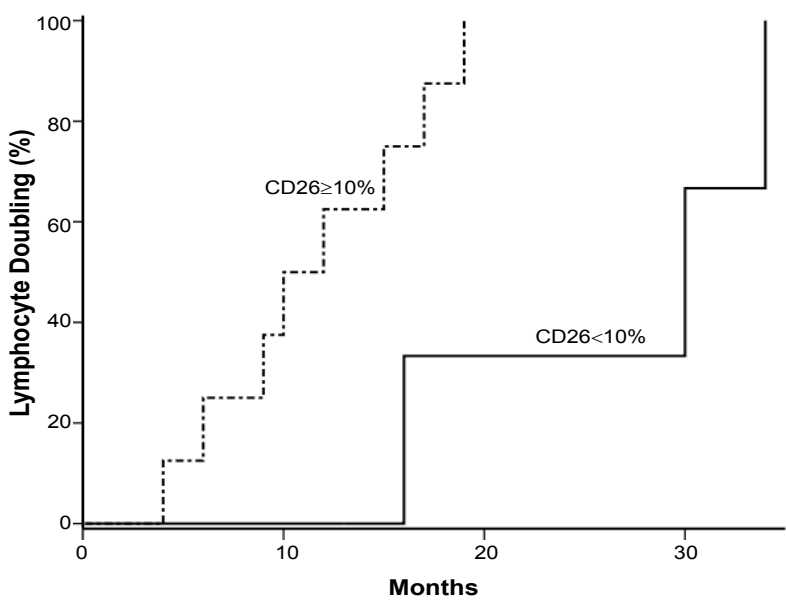

Figure 5: Lymphocytic doubling hazard according to CD26 reactivity.

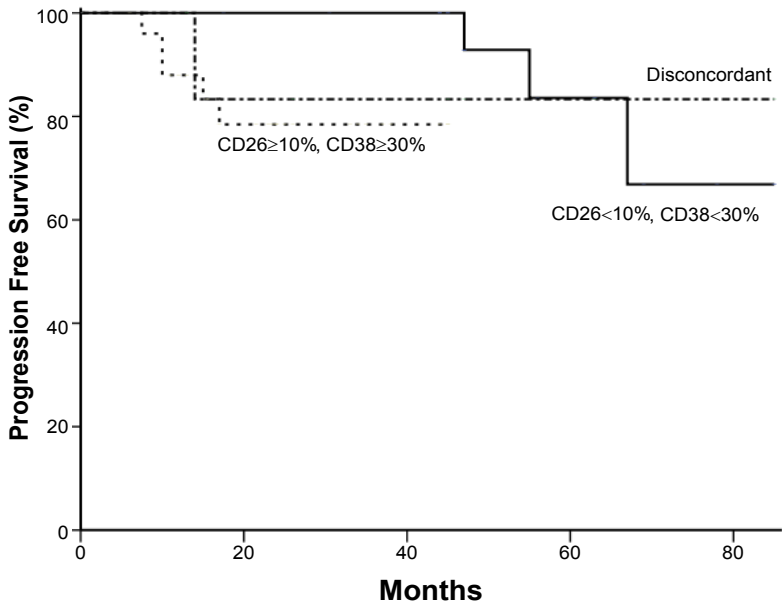

Figure 6: Progression free survival accrding to combined CD26 and CD38 expression.

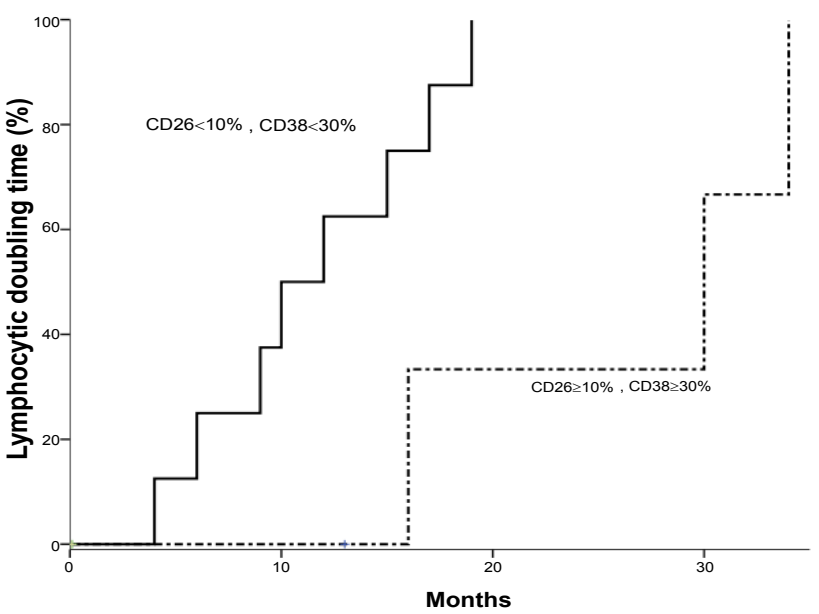

Figure 7: Lymphocytic doubling hazard according to CD26 and CD38 expression.

The relevance of $\mathrm{CD} 26$ as a prognostic marker of progressive disease was compared with that of CD38 and ZAP-70 expressions. Twenty four cases were $\mathrm{CD} 26^{\text {low }} / \mathrm{CD} 38^{\text {low }}$ and 27 were $\mathrm{CD} 26^{\text {high }} / \mathrm{CD} 38^{\text {high }}$ cases, while the remaining 7 cases were discordant for the two markers. PFS was significantly shorter in the $\mathrm{CD} 26^{\text {high }} / \mathrm{CD} 38^{\text {high }}$ than in the $\mathrm{CD} 26^{\text {low }} /$ CD38 ${ }^{\text {low }}$ cases $(37.94,76.49$ months respectively, $p=0.020$ ), but when comparing the PFS of these cases and that of the discordant cases, no significant difference was found ( $p=0.115)$ (Figure 6). Lymphocytic doubling time (LDT) was significantly shorter in the $\mathrm{CD} 26^{\text {high }} / \mathrm{CD} 38^{\text {high }}$ than in the $\mathrm{CD} 26^{\text {low }} / \mathrm{CD} 38^{\text {low }}$ cases $(\mathrm{p}=0.024)$ (Figure 7).

When we assessed the predictive power of ZAP-70 expression, there was no statistical significant difference in terms of PFS between the cases classified as ZAP-70 ${ }^{\text {low }}$ and ZAP-70 ${ }^{\text {high }}$ (log rank 0.711, $\mathrm{p}=0.399$, not shown). There were $25 \mathrm{ZAP}-70^{\text {low }} / \mathrm{CD} 26^{\text {low }}$ cases and $29 \mathrm{ZAP}$ $70^{\text {high }} / \mathrm{CD} 26^{\text {high }}$ cases; 4 showed discordant markers. The combined expression of CD26 and ZAP-70 was analyzed in relation to PFS. The estimated mean PFS in the three groups were different, 76.64 months for ZAP-70 $0^{\text {low }} / \mathrm{CD} 26^{\text {low }}, 38.37$ months for ZAP-70 $0^{\text {high }} / \mathrm{CD} 26^{\text {high }}$ patients and 62.0 months for discordant cases. After 3 years, respectively 93.3, 79.8 and $75.0 \%$ of the cases had stable disease. No significant difference was found in PFS between the three groups $(p=0.146)$. However, there was significant difference between $\mathrm{ZAP}-70^{\text {low }} / \mathrm{CD} 26^{\text {low }}$ versus $\mathrm{ZAP}$ $70^{\text {high }} / \mathrm{CD} 26^{\text {high }}$ regarding PFS ( $p=0.022$ ) (Figure 8 ). LDT was significantly shorter in the CD26 $6^{\text {high}} /$ ZAP70high than in the CD26 $6^{\text {low }} /$ ZAP70 $^{\text {low }}$ cases $(p=0.024)$ (Figure 9).

CD26, CD38, ZAP-70, Rai, absolute lymphocytic count and LDH were included in a proportional hazard regression model of Cox to test their strength as independent prognostic factors for PFS. CD26 seemed to be the sole unfavorable independent prognosticator for PFS among the biologic risk factors. According to these analyses, CD26 $6^{\text {high }}$ expression in CLL was associated with a hazard ratio (HR) for progressive disease of 1.091 (95\% confidence interval (CI), 1.037-1.148; $p=0.001)$ (Table 2).

\section{Discussion}

B- Cell neoplasms are a heterogeneous group of malignant clonal proliferations of lymphocytes [14]. B-CLL represents a B-CLPD with a high biological and clinical heterogeneity. This disease is related to 


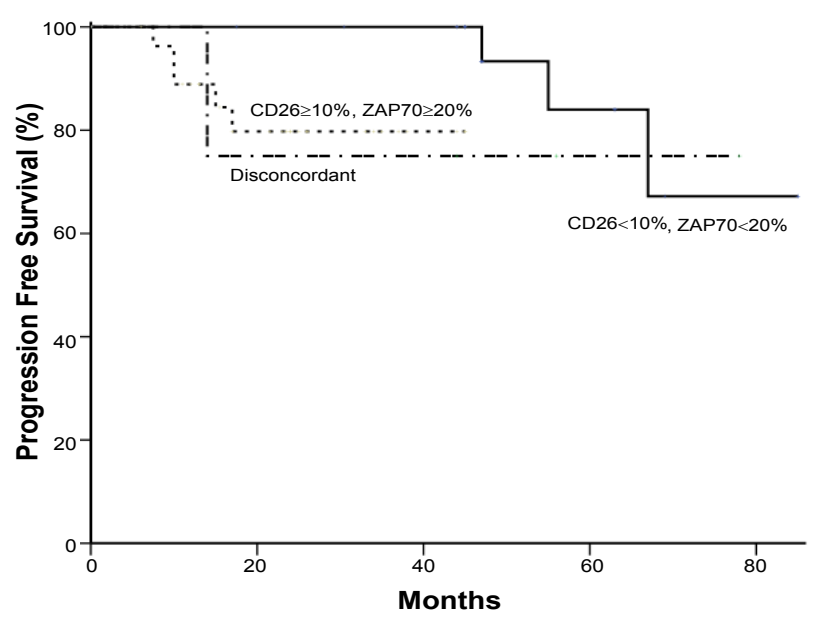

Figure 8: Progression free survival accrding to combined CD26 and ZAP70 expression.

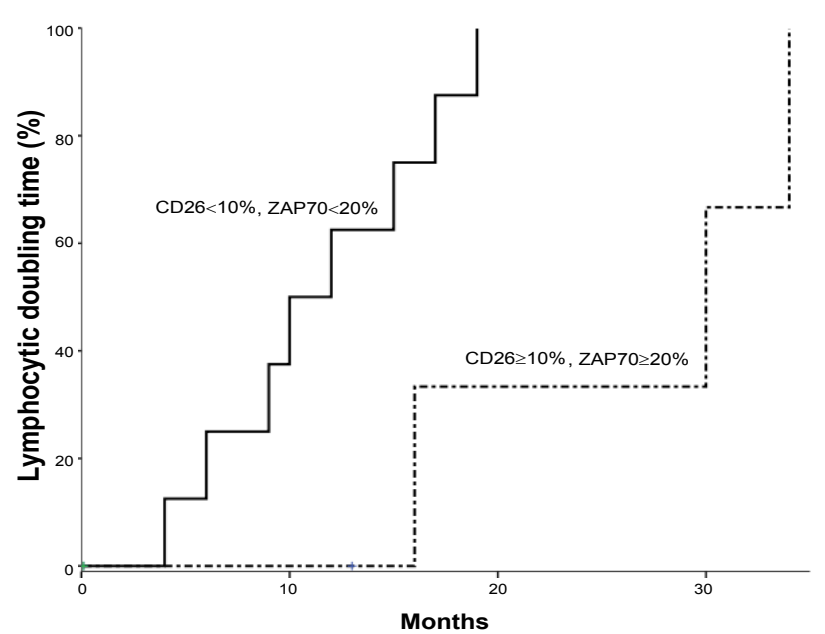

Figure 9: Lymphocytic doubling hazard according to CD26 and ZAP70 expression.

the accumulation of monoclonal B-cells with the morphology of small apparently mature lymphocytes, which is mainly due to inhibition of apoptosis rather than enhanced cell proliferation [15]. CD26 plays an important role in immune regulation, signal transduction, and apoptosis. Furthermore, CD26 appears to play an important role in tumor progression [1]. Previous studies found that CD26 status may be altered in certain malignancies and that the presence of CD26 is associated with aggressive tumours [1,2]. The aim of this study was to evaluate the expression of CD26 in patients with different forms of B-cell tumors, and its prognostic impact on B-CLL patients.

Our data show that CD26 expression is highly expressed in HCL, and heterogeneously expressed in MM, CLL and CD5neg B-CLPD, which are consistent with that reported by others [16]. CD26 was positive in $50,85.7,56.5,75 \%$, in CLL, HCL, CD5 negative LPD and MM respectively. This was confirmed by other studies [16-18]. Previous studies have reported that HCL and B-CLL can express high levels of ADA and CD26. Suggesting that their dramatic response to 2-deoxycoformycin and 2-chlorodeoxyadenosine, known inhibitors of $\mathrm{ADA}$, relates to their surface expression of the ADA-CD26 complex
$[18,19]$. Nishida et al. reported that CD26 is intensely expressed in activated osteoclasts in $\mathrm{MM}$, but not in MM cells themselves, the direct interaction between MM cells and OCs results in the up-regulation of CD26 expression in MM cells [17].

The best cut-off point for CD26 expression discriminating the patients who were diagnosed as CLL, LPD or MB-cell neoplasms from control subjects was confirmed by the cut off obtained by others $[16,20]$.

The proportion of B-CLL patients displaying high CD26 expression was equal to those displaying CD26 low expression. This was consistent with Cro et al. who reported that $58 \%$ of CLL cases had CD26 ${ }^{\text {low }}$ and $42 \%$ had CD26 $6^{\text {high }}$, [16] whereas Bouvis et al. reported that $12 \%$ of CLL cases had CD26 $6^{\text {low }}$ and $88 \%$ had CD26 $6^{\text {high }}$ [21]. The observed differences may be due to differences in sample size.

CD26 expression, in the present study, could be correlated with some clinical and laboratory markers. Patients with high CD26 expression had significantly higher incidence of splenomegaly, higher total leucocytic count, $\mathrm{LDH}$ and tendency to higher peripheral mature lymphocytes. In addition to significantly lower hemoglobin concentration and platelet count. This is in part contradictory to a number of published studies [16,20,22]. These differences may be attributed to difference in sample size, ethnic, racial and environmental factors.

The determination of, CD38 and ZAP-70 are increasingly utilized as prognostic factors for CLL [23-26]. Cut-off points of 30\% and $20 \%$ were used to define positivity for CD38 and ZAP70 respectively [26,12].

Interestingly, all our HCL cases were negative for CD38, which is considered as a germinal center-associated marker. This is approved by Forconi etal. Who found that the expression of CD38 markers

\begin{tabular}{|c|c|c|c|c|}
\hline & & $\begin{array}{l}\text { CD26 }^{\text {low }} \\
(n=29)\end{array}$ & $\begin{array}{l}\text { CD26 }^{\text {high }} \\
(n=29)\end{array}$ & $\mathbf{p}$ \\
\hline \multicolumn{2}{|l|}{ Age (years) } & $61.90 \pm 8.703$ & $59.03 \pm 9.104$ & 0.226 \\
\hline \multirow{2}{*}{ Sex } & Males & $20(69.0)$ & $20(69.0)$ & 1.000 \\
\hline & Females & $9(31.0)$ & $9(31.0)$ & \\
\hline \multicolumn{2}{|c|}{ Lymphadenopathy } & $27(93.1)$ & $28(96.6)$ & 1.000 \\
\hline \multicolumn{2}{|c|}{ Splengomegaly } & $15(51.7)$ & $23(79.3)$ & 0.027 \\
\hline \multicolumn{2}{|c|}{ Hepatomegaly } & $13(44.8)$ & $18(62.1)$ & 0.188 \\
\hline \multirow{3}{*}{ Binet stage } & $A(n=24)$ & $13(44.8)$ & $8(27.6)$ & \multirow{3}{*}{0.251} \\
\hline & $B(n=13)$ & $7(24.1)$ & $6(20.7)$ & \\
\hline & $C(n=24)$ & $9(31.0)$ & $15(51.7)$ & \\
\hline \multirow{3}{*}{ Rai stage } & $0+I(n=17)$ & $10(34.5)$ & $7(24.1)$ & \multirow{3}{*}{0.546} \\
\hline & II $(n=15)$ & $8(27.6)$ & $7(24.1)$ & \\
\hline & III+IV (n=26) & $11(37.9)$ & $15(51.7)$ & \\
\hline \multicolumn{2}{|c|}{ Total leucocytic count $\left(\mathrm{X} 10^{9} / \mathrm{I}\right)$} & $53.40 \pm 59.24$ & $97.61 \pm 91.10$ & 0.033 \\
\hline \multicolumn{2}{|c|}{$\begin{array}{l}\text { Hemoglobin concentration } \\
\text { (g/dl) }\end{array}$} & $11.35 \pm 2.33$ & $10.31 \pm 2.56$ & 0.111 \\
\hline \multicolumn{2}{|c|}{ Platelet count (X10/I) } & $198.03 \pm 77.23$ & $160.48 \pm 56.98$ & 0.040 \\
\hline \multicolumn{2}{|c|}{$\begin{array}{l}\text { Peripheral blood mature } \\
\text { lymphocytic count }\left(\times 10^{9}\right)\end{array}$} & $45.31 \pm 53.32$ & $78.98 \pm 86.68$ & 0.081 \\
\hline \multicolumn{2}{|c|}{ LDH (u/l) } & $518.24 \pm 134.50$ & $738.66 \pm 275.38$ & $<0.001$ \\
\hline \multicolumn{2}{|l|}{ CD38 low } & $24(82.8)$ & $2(6.9)$ & \multirow{2}{*}{$<0.001$} \\
\hline \multicolumn{2}{|l|}{ CD38 ${ }^{\text {high }}$} & $5(17.2)$ & $27(93.1)$ & \\
\hline \multicolumn{2}{|l|}{ ZAP70 ${ }^{\text {low }}$} & $25(86.2)$ & $0(0)$ & \multirow{2}{*}{$<0.001$} \\
\hline \multicolumn{2}{|l|}{ ZAP70 ${ }^{\text {high }}$} & $4(13.8)$ & $29(100)$ & \\
\hline
\end{tabular}

LDH: Lactate Dehydrogenase. Age, total leucocytic count, hemoglobin concentration, platelet count, peripheral blood mature lymphocytic count, LDH are presented by mean \pm SD. Sex, lymphadenopathy, splenomegaly, hepatomegaly, Binet and Rai stages, CD38 $8^{\text {high }}, \mathrm{ZAP} 70^{\text {high }}$ are presented by number and percentages

Table 1: Relationship between CD26 expression and other prognostic parameters. 
Citation: Ghannam DME, Taalab MM, Ghazy HF, Salam EMA, Fawzy IM (2014) CD26 Expression in Mature B-cell Neoplasms and its Prognostic Impact on B-Cell Chronic Lymphocytic Leukemia. J Blood Disorders Transf 5: 222. doi: 10.4172/2155-9864.1000222

Page 6 of 7

\begin{tabular}{|l|c|c|c|c|}
\hline Covariates & $\boldsymbol{p}$ & HR & \multicolumn{2}{|c|}{ 95 CI } \\
\hline Rai & 0.365 & 1.704 & 0.538 & 5.398 \\
\hline Absolute lymphocytic count & 0.405 & 1.005 & 0.993 & 1.018 \\
\hline LDH & 0.097 & 1.034 & 0.987 & 1.932 \\
\hline CD26 & 0.001 & 1.091 & 1.037 & 1.148 \\
\hline CD38 & 0.344 & 1.237 & 0.012 & 4.692 \\
\hline ZAP70 & 0.285 & 2.666 & 0.236 & 3.808 \\
\hline
\end{tabular}

HR: hazard ratio

Table 2: Progression-Free Survival as dependent parameter studied with other covariates (multivariate analysis)

confirmed the absence in HCL [27].

Our study found that CD26 reactivity closely correlates with CD38 expression in B-CLL and MM, but their reactivity patterns are different in HCL and CD5 negative CLPD. This was in agreement with some investigators [16], and disagreement with others [22]. While this may be due to the size of our cohort, it may also reflect clinical differences between the cohorts. In addition to differences in the ongoing antigen mediated activation of the neoplastic cells.

The B-CLL cases in the present study showed a statistically significant correlation between CD26/CD38, CD26/ZAP70 and CD26/ CD38/ZAP70 expressions. These data correlated with a previous publication [16]. However, others found a borderline significance for ZAP-70 $(\mathrm{P}=0.07)$ [22].

We evaluated CD26 prognostic role in terms of OS, PFS and LDT. The optimal cut-off point yielding the best separation of B-CLL patients into two subgroups with different prognoses was fixed at $10 \%$ of positive cells. This cut off was confirmed by other study [16]. B-CLL patients with high CD26 expression had significantly shorter PFS and LDT. OS showed no significant differences between high and low CD26 groups. These data correlated with previous publications [16,22]. On the other hand, others did not find any association between CD26 and survival [20].

The combined evaluation of CD26/CD38 and CD26/ZAP70 reactivities allowed us to refine the prognostic role of the combined evaluation of the molecules in comparison with their individual reactivity. The presence of both $\mathrm{CD} 26$ and/or CD38, ZAP-70 (concordant positive) is associated with B-CLL with a shorter PFS, while the absence of both CD26 and CD38, ZAP-70 (concordant negative) grouped patients were associated with a longer PFS, and the disconcordant expression of CD26 and/ or CD38, ZAP-70 was associated with an intermediate prognosis. The potential usefulness of an additional prognostic marker is supported by the results of others showing that the combined analysis of ZAP-70 and CD26 or CD38 and CD26 may be more informative than their individual evaluation [16].

CD26 shares many biological functions with CD38 [5], and may be involved in the sIgM-mediated signal competence that, in vitro, seems to unite the three important prognostic markers in B-CLL: VH-gene mutational status, CD38 and ZAP-70 [28]. Moreover CD26 expression, and particularly its DPPIV enzyme activity, induces constitutive p38 phosphorylation [29]. Which, in B-cell tumours, contributes to tumour growth [30]. In CLL B cells expressing ZAP-70, it is possible that activation (phosphorylation) of ZAP-70 via CD26 signalling, may trigger downstream events with enhanced survival signals and cell growth, resulting in a more aggressive phenotype [31-33].

Our data show that the combined analysis of CD26, CD38 and ZAP-70 identifies subgroups of patients with a different prognosis, better than their individual evaluation. And our results suggest that the

simultaneous estimate of CD26, ZAP-70, and CD38 might distinguish different B-CLL patient subgroups at least in terms of chemotherapy requirement.

These markers have a number of advantages: they can be easily evaluated by flow cytometry, which is widely used technique, and their combined evaluation in B-CLL cases may confirm the prognosis if one predictive factor is borderline. The determination of these markers and their reactivity could become a future routine panel for prognostic stratification.

Multivariate analysis showed that CD26 is an independent prognostic factor for PFS among the biologic risk factors.

In conclusion, the results of this study demonstrate the heterogeneous pattern of CD26 expression in B-cell neoplasms. CD26 expression is an unfavorable prognostic parameter in patients with B-CLL. CD26 correlates with the expression of CD38 and ZAP70 in B-CLL. We suggest its use as a part of a panel of molecules (i.e. Cd38 and ZAP70) as a new flow cytometric prognostic model.

\section{References}

1. Engel M, Hoffmann T, Wagner L, Wermann M, Heiser U, et al. (2003) The crystal structure of dipeptidyl peptidase IV (CD26) reveals its functional regulation and enzymatic mechanism. Proc Natl Acad Sci U S A 100: 5063-5068.

2. Stremenova J, Krepela E, Mares V, Trim J, Dbaly V, et al. (2007) Expression and enzymatic activity of dipeptidyl peptidase-IV in human astrocytic tumours are associated with tumour grade. Int $\mathrm{J}$ Oncol 31: 785-792.

3. Dang NH, Hagemeister FB, Duvic M, Romaguera JE, Younes A, et al. (2003) Pentostatin in T-non-Hodgkin's lymphomas: efficacy and effect on CD26+ lymphocytes. Oncol Rep 10: 1513-1518.

4. De Andrade CF, Bigni R, Pombo-de-Oliveira MS, Alves G, Pereira DA (2009) CD26/DPPIV cell membrane expression and DPPIV activity in plasma of patients with acute leukemia. J Enzyme Inhib Med Chem 24: 708-714.

5. Bühling F, Junker U, Reinhold D, Neubert K, Jäger L, et al. (1995) Functional role of CD26 on human B lymphocytes. Immunol Lett 45: 47-51.

6. Dronca RS, Jevremovic D, Hanson CA, Rabe KG, Shanafelt TD, et al. (2010) CD5-positive chronic B cell lymphoproliferative disorders: diagnosis and prognosis of a heterogeneous disease entity. Cytometry B Clin Cytom 78: S35-S41.

7. Chiorazzi N, Ferrarini M (2003) B cell chronic lymphocytic leukemia: lessons learned from studies of the B cell antigen receptor. Annu Rev Immunol 21 : 841-894.

8. Harris NL, Jaffe ES, Diebold J, Flandrin G, Muller-Hermelink HK, et al (1999) World Health Organization classification of neoplastic diseases of the hematopoietic and lymphoid tissues: report of the Clinical Advisory Committee meeting-Airlie House, Virginia. J Clin Oncol 12: 3835-3849.

9. Oscier D, Dearden C, Eren E, Fegan C, Follows G, et al. (2012) Guidelines on the diagnosis, investigation and management of chronic lymphocytic leukaemia. Br J Haematol 159: 541-564.

10. Zucchetto A, Bomben R, Bo MD, Nanni P Bulian P et al (2006) ZAP-70 expression in B-cell chronic lymphocytic leukemia: evaluation by externa (isotypic) or internal (T/NK cells) controls and correlation with $\operatorname{lgV}(\mathrm{H})$ mutations. Cytometry B Clin Cytom 70: 284-292.

11. Bulian P, Shanafelt TD, Fegan C, Zucchetto A, Cro L, et al. (2014) CD49d is the strongest flow cytometry-based predictor of overall survival in chronic lymphocytic leukemia. J Clin Oncol 32: 897-904.

12. Zucchetto A, Bomben R, Dal Bo M, Bulian P, Benedetti D, et al. (2006) CD49d in B-cell chronic lymphocytic leukemia: correlated expression with CD38 and prognostic relevance. Leukemia 20: 523-525.

13. Hallek M, Cheson BD, Catovsky D, Caligaris-Cappio F, Dighiero G, et al. (2008) Guidelines for the diagnosis and treatment of chronic lymphocytic leukemia: a report from the International Workshop on Chronic Lymphocytic Leukemia updating the National Cancer Institute-Working Group 1996 guidelines. Blood. 111: $5446-5456$ 
Citation: Ghannam DME, Taalab MM, Ghazy HF, Salam EMA, Fawzy IM (2014) CD26 Expression in Mature B-cell Neoplasms and its Prognostic Impact on B-Cell Chronic Lymphocytic Leukemia. J Blood Disorders Transf 5: 222. doi: 10.4172/2155-9864.1000222

14. Jaffe E, Harris NL, Stein H, Vardiman JW (2001) World Health Organisation Classification of Tumours. Pathology and genetics of tumours of haemopoietic and lymphoid tissues, IARC Press, Lyon.

15. Tandra P, Krishnamurthy J1, Bhatt VR1, Newman K2, Armitage JO1, et al. (2013) Autoimmune Cytopenias in Chronic Lymphocytic Leukemia, Facts and Myths. Mediterr J Hematol Infect Dis 5: e2013068.

16. Cro L, Morabito F, Zucal N, Fabris S, Lionetti M, et al. (2009) CD26 expression in mature B-cell neoplasia: its possible role as a new prognostic marker in B-CLL. Hematol Oncol 27: 140-147.

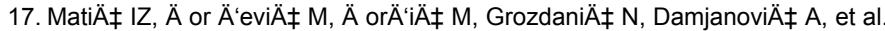
(2013) Dipeptidyl peptidase IV: serum activity and expression on lymphocytes in different hematological malignancies. Leuk Lymphoma 54: 2701-2706.

18. Pacheco R, Martinez-Navio JM, Lejeune M, Climent N, Oliva H, et al. (2005) CD26, adenosine deaminase, and adenosine receptors mediate costimulatory signals in the immunological synapse. Proc Natl Acad Sci U S A 102: 95839588.

19. Iwata S, Morimoto C (1999) CD26/dipeptidyl peptidase IV in context. The different roles of a multifunctional ectoenzyme in malignant transformation. $J$ Exp Med 190: 301-306

20. Sulda ML, Abbott CA, Macardle PJ, Hall RK, Kuss BJ (2010) Expression and prognostic assessment of dipeptidyl peptidase IV and related enzymes in B-cell chronic lymphocytic leukemia. Cancer Biol Ther 10: 180-189.

21. Bauvois B, De Meester I, Dumont J, Rouillard D, Zhao HX, et al. (1999) Constitutive expression of CD26/dipeptidylpeptidase IV on peripheral blood B lymphocytes of patients with $\mathrm{B}$ chronic lymphocytic leukaemia. $\mathrm{Br} \mathrm{J}$ Cancer 79 : 1042-1048.

22. Molica S, Digiesi G, Mirabelli R, Cutrona G, Antenucci A, et al. (2009) Serum level of CD26 predicts time to first treatment in early B-chronic lymphocytic leukemia. Eur J Haematol 83: 208-214.

23. Wiestner A, Rosenwald A, Barry TS, Wright G, Davis RE,et al. (2003) ZAP-70 expression identifies a chronic lymphocytic leukemia subtype with unmutated immunoglobulin genes,inferior clinical outcome, and distinct gene expression profile. Blood. 101: 4944-4951.
24. Crespo M, Bosch F, Villamor N, Bellosillo B, Colomer D, et al. (2003) ZAP70 expression as a surrogate for immunoglobulin-variable-region mutations in chronic lymphocytic leukemia. N Engl J Med 348: 1764-1775.

25. Orchard JA, Ibbotson RE, Davis Z, Wiestner A, Rosenwald A, et al. (2004) ZAP-70 expression and prognosis in chronic lymphocytic leukaemia. Lancet 363: 105-111.

26. Rassenti LZ, Huynh L, Toy TL, Chen L, Keating MJ, et al. (2004) ZAP70 compared with immunoglobulin heavy-chain gene mutation status as predictor of disease progression in chronic lymphocytic leukemia. N Engl $J$ Med 351: 893-901.

27. Forconi F, Sahota SS, Raspadori D, Ippoliti M, Babbage G, et al. (2004) Hairy cell leukemia: at the crossroad of somatic mutation and isotype switch. Blood 104: 3312-3317.

28. Mockridge Cl, Potter KN, Wheatley I, Neville LA, Packham G, et al. (2007) Reversible anergy of slgM-mediated signaling in the two subsets of CLL defined by VH-gene mutational status. Blood 109: 4424-4431.

29. Yamochi T, Yamochi T, Aytac U, Sato T, Sato K, et al. (2005) Regulation of p38 phosphorylation and topoisomerase llalpha expression in the B-cell lymphoma line Jiyoye by CD26/dipeptidyl peptidase IV is associated with enhanced in vitro and in vivo sensitivity to doxorubicin. Cancer Res 65: 1973-1983.

30. Ogasawara T, Yasuyama M, Kawauchi K (2003) Constitutive activation of extracellular signal-regulated kinase and p38 mitogen-activated protein kinase in B-cell lymphoproliferative disorders. Int J Hematol 77: 364-370.

31. Kähne T, Neubert K, Faust J, Ansorge S (1998) Early phosphorylation events induced by DPIV/CD26-specific inhibitors. Cell Immunol 189: 60-66.

32. Degheidy HA, Venzon DJ, Farooqui MZ, Abbasi F, Arthur DC, et al. (2011) Improved ZAP-70 assay using two clones, multiple methods of analysis and clinical correlation. Cytometry B Clin Cytom. 80: 309-317.

33. Ishii T, Ohnuma K, Murakami A, Takasawa N, Kobayashi S, et al. (2001) CD26-mediated signaling for $T$ cell activation occurs in lipid rafts through its association with CD45RO. Proc Natl Acad Sci U S A 98: 12138-12143.
Citation: Ghannam DME, Taalab MM, Ghazy HF, Salam EMA, Fawzy IM (2014) CD26 Expression in Mature B-cell Neoplasms and its Prognostic Impact on B-Cell Chronic Lymphocytic Leukemia. J Blood Disorders Transf 5: 222. doi: 10.4172/2155-9864.1000222 